\title{
Inclusão de farinha de resíduos da indústria de filetagem de tilápias na alimentação de girinos de rã-touro (Rana Catesbeiana Shaw,1802)
}

\section{Meal from tilapia filleting industrial waste in the feed of the bullfrog tadpoles (Rana Catesbeiana Shaw, 1802)}

\author{
Leonardo Luiz Stringuetta ${ }^{1 *}$; Wilson Rogério Boscolo ${ }^{2}$; Aldi Feiden; \\ Bruno Estevão de Souza ${ }^{3}$; Cleiton Manske ${ }^{4}$; Cleverson Luiz de Oliveira ${ }^{4}$
}

Resumo

\begin{abstract}
Este experimento objetivou avaliar a inclusão da farinha de resíduos de filetagem de tilápias (FT) em rações para girinos de rã-touro (Rana Catesbeina Shaw,1802). Foram utilizados 250 girinos com peso e comprimento inicial de $0,18 \pm 0,05 \mathrm{~g}$ e 2,50 $\pm 0,18 \mathrm{~cm}$, respectivamente, distribuídos em 25 aquários de 30 $\mathrm{L}$ cada, em um delineamento inteiramente casualizado com cinco tratamentos e cinco repetições. Os girinos foram alimentados quatro vezes ao dia, com rações contendo $0,5,10,15 \%$ de inclusão de FT e outra ração com $0 \%$ de FT suplementada com metionina sintética, sendo fornecidas quatro vezes ao dia a vontade. O período do experimento foi de 30 dias. As rações com inclusão de FT e suplementação de metionina não influenciaram nas médias de peso final, comprimento final, sobrevivência e conversão alimentar dos girinos de rã-touro. Pode-se utilizar até 15\% de inclusão de FT na alimentação de girinos de rã-touro. A suplementação de metionina sintética em rações para girinos de rã-touro não é necessária em rações com níveis acima de $0,47 \%$ de metionina total.
\end{abstract}

Palavras-chave: Ração, ranicultura, avaliação de alimentos alternativos

\begin{abstract}
The objective of this experiment was to evaluate the inclusion of meal of tilapia industrial waster in bullfrog tadpoles' diets (Rana Catesbeina Shaw, 1802). Two hundred fifty tadpoles with initial weight and length of $0,18 \pm 0,05 \mathrm{~g}$ and 2,50 $\pm 0,18$ centimeters were used, respectively, they were used and distributed in 25 aquariums of 30 liter each in a complete randomized design with five treatments and five repetitions. The tadpoles were fed four times a day with diets containing $0,5,10$ and $15 \%$ of inclusion of tilapia filleting and another diet with $0 \%$ of supplemented tilapia filleting with synthetic methionine, being supplied four times a day at ease. The experiment period was 30 days. The diets with tilapia filleting inclusion and methionine supplementation did not have influence in the final weight and length averages, feed survival and conversion of bullfrog tadpoles. It cam be used until $15 \%$ of tilapia filleting inclusion in the bullfrog tadpoles food. The synthetic methionine supplementation in diets for bullfrog tadpoles is not necessary in diets with levels over $0,47 \%$ of the total methionine.
\end{abstract}

Key words: Fed, frog production, alternative food evaluation

\footnotetext{
1 Acadêmico do curso de Engenharia de Pesca- UNIOESTE - Campus.Toledo-Pr. Email: leostringuetta@ zipmail.com.br.

2 Professores Adjuntos da UNIOESTE- Campus. Toledo-Pr.

3 Engenheiro de Pesca, Mestrando do Centro de Aqüicultura da UNESP - CAUNESP, Jaboticabal, SP.

4 Aluno do curso de Engenharia de Pesca- UNIOESTE -Campus. Toledo-Paraná.

* Autor para correspondência
} 


\section{Introdução}

A ranicultura é hoje uma atividade zootécnica intensiva, que ocupa relativamente pouco espaço e apresenta-se como uma boa alternativa econômica. Dentre os aspectos considerados como necessários para obtenção de melhores resultados no cultivo de rãs, Culley Júnior apud De Stéfani et al. (2001) já destacavam a utilização e o aperfeiçoamento de técnicas de alimentação e nutrição, sugerindo ainda que os elevados índices de mortalidade observados nos ranários comerciais possam estar relacionados a deficiências na alimentação dos animais.

A criação de rãs ainda é considerada uma atividade exótica, incipiente e com muitos desafios a serem enfrentados. Por outro lado, há de se registrar as recentes conquistas tecnológicas e as perspectivas de demanda do mercado que se apresentam para a atividade (LIMA; CRUZ; MOURA, 1999). A ranicultura no Brasil vem sendo uma alternativa de renda para pequenos produtores, e fonte de rendas para os grandes, que já contam com a exportação de sua carne. Para se obter melhores resultados no desenvolvimento da ranicultura, estão sendo realizados vários estudos, principalmente no que diz respeito a sua nutrição, um dos pontos principais para seu bom desempenho.

Na ranicultura, a fase de criação de girinos é de muita importância, pois dela depende a quantidade e qualidade dos animais a serem obtidos para a fase de engorda. O uso de técnicas adequadas de alimentação, profilaxia de doenças e obtenção de bons reprodutores é essencial para proporcionar melhorias no cultivo de girinos. Grande parcela de êxito na produção de girinos cabe, primordialmente, à alimentação nesse estágio de desenvolvimento, no qual devem receber adequadas proporções de nutrientes através de uma dieta balanceada. Entretanto, para se formular uma dieta de girinos, como para qualquer outra espécie, é preciso conhecer suas exigências nutricionais em relação a proteína, energia, fibra, extrato etéreo, carboidratos, minerais e vitaminas (DE STÉFANI; MARCOANTONIO; MARTINS, 2001), o valor nutritivo dos alimentos para proporcionar um desenvolvimento adequado aos animais e seu processamento (DE STÉFANI; MARCANTONIO, 1997).

Alguns parâmetros nutricionais começam a ser delineados na nutrição de rãs a partir de ensaios de digestibilidade realizados por ALBINATI et al. (2000) e de avaliação de desempenho visando determinar as exigências de proteína bruta e de energia (digestível ou metabolizável) (SEIXAS-FILHO et al., 1998).

Com o notável crescimento e intensificação da aqüicultura mundial (BORGHETTI; OSTRENSKY; BORGHETTI, 2003), a demanda por ingredientes de alta qualidade para formulação de rações, tem aumentado. Aliado a este fato, a disponibilidade de farinha de peixe tem diminuído e seu custo aumentado, criando a necessidade da pesquisa de fontes protéicas alternativas (EL-SAYED, 1999; SUGIURA et al., 2000).

A indústria de filetagem de tilápias gera grande quantidade de resíduos, produzindo cerca de $70 \%$ de resíduos constituídos por cabeça, nadadeiras, vísceras, pele e escamas, coluna vertebral e aparas. Estes materiais, ricos em nutrientes, têm sido bem aproveitados para confecção de farinha de alto valor protéico na região oeste do Paraná, reduzindo assim o custo de produção das indústrias. A farinha de resíduos da indústria de filetagem de tilápias apresenta coeficiente de digestibilidade aparente da matéria seca de $83,55 \%$, apresenta ainda $44,39 \%$ de proteína digestível e $3799 \mathrm{kcal}$ de energia digestível/kg para tilápias, demonstrando alto potencial para ser utilizada em rações (BOSCOLO, 2003).

O objetivo do presente trabalho foi avaliar o desempenho de girinos da rã-touro (Rana Catesbeina Shaw , 1802) alimentados com rações em diferentes níveis de inclusão de farinha de resíduos de tilápia e a suplementação de metionina sintética a dieta controle.

\section{Material e Métodos}

O experimento foi realizado no Laboratório de Aqüicultura da Universidade Estadual do Oeste do 
Paraná - UNIOESTE/TOLEDO, com duração de 30 dias. Foram utilizados 250 girinos de rã- touro (Rana catesbeiana Shaw,1802) com peso e comprimento inicial de $0,18 \pm 0,05 \mathrm{~g}$ e $2,50 \pm 0,18 \mathrm{~cm}$, respectivamente, e com 30 dias após a eclosão, correspondendo ao estágio G1, com peso inicial médio de $0,18 \mathrm{~g}$, distribuídos em 25 aquários com capacidade para 30 litros de água, em um delineamento inteiramente casualisado com cinco tratamentos e cinco repetições, sendo a unidade experimental constituída por um aquário com 10 girinos.

Os aquários apresentaram sistema de aeração individual, conectados por mangueiras a um soprador central. Foram realizadas renovações diárias de cerca de $20 \%$ do volume total no início do experimento e $50 \%$ nos últimos 15 dias, por meio de duas sifonagens, uma no período da manhã antes da primeira alimentação e outra no final da tarde antes da última alimentação.
Foram elaboradas cinco rações com níveis de 0 (controle); 5; 10; 15\% de inclusão da farinha de resíduos da indústria de filetagem de tilápias (FT) e a ração controle com suplementação de metionina através da adição de metionina sintética (DLMetionina 99\%). As rações experimentais foram formuladas de modo a serem isoprotéicas, isoenergéticas, isocalóricas, isocálcicas e isofosfóricas (Tabela 1). Para a elaboração das rações experimentais, os alimentos foram moídos individualmente e posteriormente misturados. Os valores de composição química e nutrientes digestíveis da FT e dos outros alimentos foram baseados em Boscolo, Hayashi e Meurer (2002) e Boscolo (2003) e as exigências nutricionais foram baseadas em exigências para peixes segundo National Research Council (1993) e dados de SeixasFilho et al. (1998).

Tabela 1. Composição percentual e química das rações experimentais com diferentes níveis de inclusão de farinha de resíduos da indústria de filetagem de peixes na alimentação de girinos de rã-touro (matéria natural).

\begin{tabular}{|c|c|c|c|c|c|}
\hline \multirow[t]{2}{*}{ Alimentos (\%) } & \multicolumn{5}{|c|}{ Níveis de inclusão (\%) } \\
\hline & 0 & 5 & 10 & 15 & $0+$ met \\
\hline Milho & 12,00 & 13,36 & 14,73 & 16,10 & 11,98 \\
\hline Farelo de soja & 64,51 & 58,22 & 51,93 & 45,65 & 64,50 \\
\hline Farelo de trigo & 14,30 & 16,79 & 19,26 & 21,73 & 14,25 \\
\hline Farinha de resíduos de tilápias & 0,00 & 5,00 & 10,00 & 15,00 & 0,00 \\
\hline Óleo de soja & 3,87 & 2,58 & 1,29 & 0,00 & 3,87 \\
\hline DL-metionina $99 \%$ & 0,00 & 0,00 & 0,00 & 0,00 & 0,08 \\
\hline Calcário calcítico & 2,00 & 1,33 & 0,67 & 0,00 & 2,00 \\
\hline Fosfato bicálcico & 1,8 & 1,20 & 0,60 & 0,00 & 1,80 \\
\hline Sal comum & 0,50 & 0,50 & 0,50 & 0,50 & 0,50 \\
\hline Suplemento min. + vit. ${ }^{1}$ & 1,00 & 1,00 & 1,00 & 1,00 & 1,00 \\
\hline Antioxidante (BHT) & 0,02 & 0,02 & 0,02 & 0,02 & 0,02 \\
\hline Total & 100,00 & 100,00 & 100,00 & 100,00 & 100,00 \\
\hline \multicolumn{6}{|l|}{ Composição } \\
\hline Energia digestível(kcal/kg) & 3.069 & 3.069 & 3.069 & 3.069 & 3067 \\
\hline Proteína bruta & 33,52 & 33,54 & 33,55 & 33,57 & 33,55 \\
\hline Gordura & 5,62 & 5,47 & 5,33 & 5,16 & 5,62 \\
\hline Fibra & 5,33 & 5,21 & 5,09 & 4,96 & 5,33 \\
\hline Lisina & 1,91 & 1,91 & 1,910 & 1,91 & 1,91 \\
\hline Metionina & 0,47 & 0,50 & 0,52 & 0,55 & 0,55 \\
\hline Metionina+cistina & 1,14 & 1,16 & 1,17 & 1,19 & 1,21 \\
\hline Amido & 20,45 & 21,19 & 21,93 & 22,67 & 20,42 \\
\hline Cálcio & 1,32 & 1,319 & 1,32 & 1,32 & 1,32 \\
\hline Fosfato total & 0,88 & 0,89 & 0,91 & 0,93 & 0,88 \\
\hline Linolêico & 3,10 & 2,33 & 1,65 & 0,98 & 3,00 \\
\hline
\end{tabular}

${ }^{1}$ Níveis de garantia por quilograma do produto: Vit. A, 500.000UI; Vit. D , 200.000UI; Vit. E, 5.000mg; Vit. K3, 1.000mg; Vit. B1, 1.500mg; Vit. B2, 1.500mg; Vit. B6, 1.500mg; Vit. B12, 4.000mg; Ác. Fólico, 500mg; Pantotenato Ca, 4.000mg; Vit. C, 15.000mg; Biotina, 50mg; Inositol, 10.000; Nicotinamida, 7.000; Colina, 40.000mg; Co, 10mg; Cu, 500mg; Fe, 5.000mg; I, 50mg; Mn, $1500 \mathrm{mg}$; Se, 10mg; Zn, $5.000 \mathrm{mg}$. 
O arraçoamento foi realizado à vontade, com freqüência de quatro vezes ao dia, sendo duas no período da manhã e duas no período da tarde (8:00; 11:00; 15:00 e 18:00hs).

Os parâmetros físico-químicos como pH, oxigênio dissolvido, condutividade elétrica da água foram mensurados semanalmente, enquanto a temperatura da água foi monitorada diariamente duas vezes ao dia, sendo uma no período da manhã e outra a tarde.

Ao final do período experimental os girinos foram pesados e medidos para avaliação do peso final médio, comprimento final médio, sobrevivência e conversão alimentar aparente. As médias obtidas foram submetidas a análise estatística (análise de variância - ANOVA) ao nível de 5\% de probabilidade utilizando-se o programa estatístico SAEG (Sistema de Análises Estatísticas e Genética) (UNIVERSIDADE FEDERAL DE VIÇOSA, 1997).

\section{Resultados e Discussão}

As médias dos parâmetros de temperatura, oxigênio dissolvido, $\mathrm{pH}$ e condutividade, durante o período experimental, foram de $27 \pm 2,17^{\circ} \mathrm{C}, 6,59 \pm$ $0,52 \mathrm{mg} / \mathrm{L}, 7,83 \pm 0,16$ e $77,11 \pm 1,01 \mathrm{mS} / \mathrm{cm}$ respectivamente, permanecendo dentro dos níveis aceitáveis para a aqüicultura. Segundo Braga e Lima (2001) a melhor faixa de temperatura para desenvolvimento da rã-touro é de 25 a $30^{\circ} \mathrm{C}$.

Os valores médios de desempenho dos girinos de rã-touro estão apresentados na Tabela 2.

Tabela 2. Valores médios de desempenho de girinos de rã-touro alimentados com rações contendo diferentes níveis de inclusão de farinha de tilápia e suplemento com metionina sintética.

\begin{tabular}{lcccccc}
\hline & \multicolumn{3}{c}{ Tratamentos } & \\
\cline { 2 - 5 } Variáveis* $^{*}$ & 0 & 5 & 10 & 15 & 0 0+metionina & CV \% \\
\hline Peso inicial médio (g) & 0,18 & 0,18 & 0,18 & 0,18 & 0,18 & 2,18 \\
Peso final médio (g) & 0,45 & 0,37 & 0,41 & 0,39 & 0,44 & 10,92 \\
Comprimento dos girinos (cm) & 3,38 & 3,22 & 3,26 & 3,24 & 3,30 & 3,53 \\
Viabilidade (\%) & 92 & 100 & 98 & 98 & 96 & 4,38 \\
Conversão Alimentar Aparente & 1,58 & 2,18 & 1,75 & 1,74 & 1,55 & 21,18 \\
\hline
\end{tabular}

${ }^{*}(\mathrm{P}>0,05)$.

Não foram observadas diferenças nas médias de peso final, comprimento final, sobrevivência e conversão alimentar de girinos de rã-touro alimentados com rações contendo diferentes níveis de inclusão de farinha de resíduos da indústria de filetagem, e a ração controle com suplementação de metionina sintética. Estes resultados discordam de Crivelenti (1992) que observou melhores resultados no desempenho de girinos de rã-touro alimentados com rações contendo $25 \%$ da proteína total de fonte de origem animal.

Os resultados do presente trabalho concordam com Seixas-Filho et al. (1998), que avaliaram o efeito de energia e proteína em rações para girinos de rãtouro avaliaram rações contendo de 25,35 e $45 \%$ de PB com conseqüente variação da relação de ingredientes de origem animal e vegetal sendo que não foram observadas diferenças no desempenho dos girinos.

Signor et al. (2004a) avaliando rações com a mesma formulação utilizada neste experimento para alevinos de tilápia do Nilo observaram melhores resultados de desempenho para os peixes que receberam rações contendo a farinha de resíduos da indústria de filetagem de tilápias. No entanto, a ração com suplementação com metionina sintética não diferiu da ração sem a farinha de tilápias quanto ao desempenho dos animais. Por outro lado, Signor et al. (2004b) observaram que a inclusão de farinha de resíduos da indústria de filetagem de tilápias em rações para alevinos de piavuçu melhorou as médias de comprimento final e conversão alimentar dos 
peixes. Observaram também que a suplementação de rações à base de alimento de origem vegetal com metionina sintética melhorou o desempenho dos animais. Estes trabalhos demonstram diferenças na utilização de diferentes fontes alimentares pelas diversas espécies de animais aquáticos.

Embora as inclusões com a farinha de resíduos da filetagem de tilápias tenham aumentado os teores de aminoácidos nas rações como a metionina (Tabela 1), este fato não melhorou o desempenho dos girinos. Isto pode ser explicado devido a alta digestibilidade do farelo de soja por girinos de rã-touro conforme Albinati et al. (2000) que observaram melhores resultados de digestibilidade para farinha de soja do da farinha de peixe, apresentando coeficientes de digestibilidade da proteína e energia de 99,12 e 94,26\% para o farelo de soja e 86,77 e 78,96\% para a farinha de peixe, respectivamente. Este fato demonstra que os girinos de rã-touro são bastante versáteis no aproveitamento de diversas fontes protéicas, tanto de origem animal como vegetal.

\section{Conclusões}

Pelo presente trabalho pode-se concluir que a alimentação de girinos de rã touro a base de proteína de farelo de soja pode ser substituída por até $15 \%$ de inclusão de farinha de resíduos de filetagem de tilápias, sem alteração no seu desempenho, e que não é necessário suplementar metionina quando esta apresentar níveis de $0,47 \%$.

\section{Referências}

ALBINATI, R. C. B.; LIMA S. L.; TAFURI M. L.; DONZELE, J. L. Digestibilidade aparente de dois alimentos protéicos e três energéticos para girinos de rã-touro (Rana Catesbeiana, Shaw, 1802). Revista Brasileira de Zootecnia, Viscosa, v.6, n.29, p.2151-2156, 2000.

BORGHETTI, N. R. B.; OSTRENSKY, A.; BORGHETTI, J. R. Aqüicultura: uma visão geral sobre a produção de organismos aquáticos no Brasil e no mundo. Curitiba: Grupo Integrado de Aqüicultura e Estudos Ambientais, 2003.
BOSCOLO, W. R. Farinha de resíduos da indústria de filetagem de tilápias na alimentação da tilápia do Nilo (Oreochromis niloticus L.). 2003. Tese (Doutorado em Produção Animal) - Universidade Estadual de Maringá, Maringá.

BOSCOLO, W. R.; HAYASHI, C.; MEURER, F. Digestibilidade aparente da energia e nutrientes de alimentos convencionais e alternativos para a tilápia do Nilo (Oreochromis niloticus, L.). Revista Brasileira de Zootecnia, Viçosa, v.13, n.2, p.539-545, 2002.

BRAGA, L. G. T.; LIMA, S. L. Influência da temperatura ambiente no desempenho da rã-touro, Rana Catesbeiana (Shaw, 1802) na fase de recria. Revista Brasileira de Zootecnia, Viçosa, v.6, n.30, p.1659-1663, 2001.

CRIVELENTI, G. Níveis protéicos e proporções de proteina de origem animal em dietas artificiais para girinos de rã touro (Rana catesbeiana Shaw, 1802). 1992. Monografia (Graduação em Zootecnia) - Universidade Estadual Paulista, Jaboticabal.

DE STÉFANI, M. V.; BRAGA, L. G. T.; PRIM, E. C. P.; ALBINATI, R. C. B. Nutrição e alimentação em ranicultura. In: ENCONTRO NACIONAL DE RANICULTURA, 11., 2001, Bragança Paulista. Cursos... Bragança Paulista: ABETRA, 2001a. p.63-89.

DE STÉFANI, M. V.; MARCANTONIO, A. S. Efeito do processamento da ração e o uso de aglutinantes no desempenho de girinos de rã touro (Rana catesbeiana Shaw, 1802). Boletim do Instituto de Pesca, São Paulo, v.24, n.especial, p.205-212, 1997.

DE STÉFANI, M. V.; MARCANTONIO, A. S.; MARTINS, M. L. Suplementação com vitamina $\mathrm{C}$ e E sobre o desenvolvimento e sobrevivência de girinos de rã touro (Rana catesbeiana Shaw, 1802). Ciência Rural, Santa Maria, v.31, n.5, p.869-871, 2001b.

EL-SAYED, A. F. M. Alternative dietary protein sources for farmed tilapia, Oreochromis spp. Aquaculture, Amsterdam, v.179, n.1, p.149-168, 1999.

LIMA, S. L.; CRUZ, T. A.; MOURA, O. M. Ranicultura: análise da cadeia produtiva. Viçosa: Folha de Viçosa, 1999. v.1.

NATIONAL RESEARCH COUNCIL. NRC. Nutrient requirements of warmwater, fishes and shellfishes: nutrient requirements of domestics animals. Washington. D.C.: National Academy Press, 1993.

SEIXAS-FILHO, J. T.; MELLO, S. C. R. P.; SILVA, J. M. F.; THOMAS, J. E.; MELO, C. M. S. Efeito de níveis de energia e proteína bruta no desempenho de girinos (Rana catesbeiana Shaw, 1802), Revista Brasileira de Zootecnia, Viçosa, v.27, n.4, p.664-669, 1998. 
SIGNOR, A., FEIDEN A., BOSCOLO, W. R., SIGNOR, A. A.; BOMBARDELLI, R. A.; ISHIDA, F. A. Farinha de resíduo da filetagem de tilápias em rações para alevinos de piavuçú (Leporinus macrocphalus). In: REUNIÃO ANUAL DA SOCIEDADE BRASILEIRA DE ZOOTECNIA, 41., 2004, Campo Grande. Anais... Campo Grande: SBZ, 2004b. CD ROM.

SIGNOR, A.; FEIDEN, A.; BOSCOLO, W. R., BOMBARDELLI, R. A.; SIGNOR, A. A.; REIDEL, A. Farinha de resíduos de filetagem de tilápia em rações para alevinos de tilápia do Nilo Oreochromis niloticus. In: REUNIÃO ANUAL DA SOCIEDADEBRASILEIRADE ZOOTECNIA, 41., 2004, Campo Grande. Anais... Campo Grande: SBZ, 2004a. CD ROM.
SUGIURA, S. H., BABBITT, J. K., DONG, F. M.; HARDY, R. W. Utilization of fish and animal by-product meals in low-pollution feeds for rainbow trout Oncorhynchus mykiss (Walbaum). Aquaculture Research, Oxford, v.31, n.7, p.585-593, 2000.

UNIVERSIDADE FEDERAL DE VIÇOSA - UFV. Sistema para análises estatísticas e genéticas - SAEG. Versão 7.1. Viçosa, MG, 1997. (Manual do Usuário). 